\title{
Orientation Selection and Microstructural Evolution in Directionally Solidified $\mathrm{Tb}_{0.3} \mathrm{Dy}_{0.7} \mathrm{Fe}_{1.95}$
}

\author{
MITHUN PALIT, S. BANUMATHY, A.K. SINGH, S. PANDIAN, \\ and KAMANIO CHATTOPADHYAY
}

\begin{abstract}
$\mathrm{Tb}_{0.3} \mathrm{Dy}_{0.7} \mathrm{Fe}_{1.95}$ alloy was directionally solidified by using a modified Bridgman technique at a wide range of growth rates of 5 to $100 \mathrm{~cm} / \mathrm{h}$. The directionally grown samples exhibited plane front solidification morphology up to a growth rate of $90 \mathrm{~cm} / \mathrm{h}$. Typical island banding feature was observed closer to the chilled end, which eventually gave rise to irregular peritectic coupled growth (PCG). The PCG gained prominence with an increase in the growth rate. The texture study revealed formation of strong $\langle 311\rangle$ texture in a lower growth rate regime, $\langle 110\rangle$ and "rotated $\langle 110\rangle$ " in an intermediate growth regime, and $\langle 112\rangle$ in a higher growth rate regime. In-depth analysis of the atomic configuration of a solid-liquid interface revealed that the growth texture is influenced by the kinetics of atomic attachment to the solid-liquid interface, which is intimately related to a planar packing fraction and an atomic stacking sequence of the interfacial plane. The mechanism proposed in this article is novel and will be useful in addressing the orientation selection mechanism of topologically closed packed intermetallic systems. The samples grown at a higher growth rate exhibit larger magnetostriction $(\lambda)$ and $\mathrm{d} \lambda /$ $\mathrm{dH}$ owing to the absence of pro-peritectic ( $\mathrm{Tb}, \mathrm{Dy}) \mathrm{Fe}_{3}$ and formation of $\langle 112\rangle$ texture, which lies closer to the easy magnetization direction (EMD).
\end{abstract}

DOI: $10.1007 / \mathrm{s} 11661-016-3345-6$

(c) The Minerals, Metals \& Materials Society and ASM International 2016

\section{INTRODUCTION}

SINCE the discovery of anisotropy compensated giant magnetostrictive $\mathrm{Tb}_{0.3} \mathrm{Dy}_{0.7} \mathrm{Fe}_{1.95}$, a substantial research effort has been underway to engineer the material to make it suitable for transducer applications. ${ }^{[1-3]}$ Achieving large magnetostriction in this compound at a small applied magnetic field essentially requires the development of a grain orientation closer to the easy magnetization direction (EMD) $\langle 111\rangle$ by using directional solidification (DS) techniques. To develop grain orientation in the cylindrical rods of this material, methods such as zone melting (for diameter $\leq 8 \mathrm{~mm}$ ) and modified Bridgman (for diameter $\geq 10 \mathrm{~mm}$ ) are generally adopted. ${ }^{[4-8]}$ The processing parameters of directional solidification techniques such as temperature gradient $(\mathrm{G})$ and solidification rate $(\mathrm{v})$ have a profound influence on the postsolidification microstructure and evolution of the texture. Therefore, an in-depth understanding of directional solidification of the $(\mathrm{Tb}, \mathrm{Dy}) \mathrm{Fe}_{2}$ intermetallic is the topic of interest with a special emphasis on orientation selection and microstructural evolution. Several researchers, including the authors, ${ }^{[-15]}$ are pursuing investigations in this area, and

MITHUN PALIT and S. PANDIAN, Scientists, are with the Advanced Magnetics Group, Defense Metallurgical Research Laboratory, Kanchanbagh, Hyderabad 500 058, India. Contact e-mail: mithunpalit@gmail.com S. BANUMATHY and A.K. SINGH, Scientists, are with the Structural Failure Analysis Group, Defense Metallurgical Research Laboratory. KAMANIO CHATTOPADHYAY, Professor, is with the Department of Materials Engineering, Indian Institute of Science, Bangalore 560 012, India.

Manuscript submitted July 8, 2015.

Article published online February 4, 2016 the efforts have led to an improved know-how of the physical metallurgical aspects of this material. However, the key issue that remains unresolved is to grow the material successfully with $\langle 111\rangle$ texture. A few reports, including one by Wu et al. ${ }^{116]}$ show that it is possible to grow the $\langle 111\rangle$-oriented single crystal by using the Czochralski technique with a seed crystal. However, this method restricts the dimension of the crystal that can be grown. On the other hand, zone melting or modified Bridgman techniques offer scope for obtaining specimens of larger dimensions. Although reports on formation of different texture components through these methods are available, ${ }^{[4-15]}$ an integrated theory on the underlying mechanism is yet to evolve that can explain the orientation selection as a function of solidification parameters.

In an earlier report, ${ }^{[13]}$ we addressed the issue of texture selection during crystal growth by using the zone melting technique. We observed that the growth conditions favored cellular/dendritic solidification morphology over a wide range of growth rates, but we did not observe the formation of $\langle 111\rangle$ texture. Rather, formation of $\langle 112\rangle$ texture was noted at a higher growth rate regime and $\langle 110\rangle$ in a lower growth rate regime. Our attempt to explain such an orientation selection mechanism revealed that it is important to have an in-depth understanding about the planes that enclose the crystal along the growth direction. We noted that the envelope of growth planes along $\langle 112\rangle$ has a kinetic advantage over the envelope around the $\langle 110\rangle$ growth direction when one considers atomic accommodation during the growth, in relation to the stacking sequence of constituent planes of growth envelopes. 
In line with the argument proposed by us (Figure 1(a)), we noted that for $\langle 111\rangle$ growth in the cellular/dendritic regime, the growth envelope contains three $\{111\}$ type planes forming a tetrahedron (Figure 1(b)). Since the $\{111\}$ type planes have alternate layers of rare earth $(\mathrm{R})$ and $\mathrm{R}+\mathrm{Fe}$ in its stacking sequence, its growth is extremely sluggish (Figure 7). As a result, growth of $\langle 111\rangle$ texture will be less preferred compared with $\langle 112\rangle$. Therefore, it would be difficult to grow material textured along $\langle 111\rangle$ in the cellular/dendritic regime. Thus, the only option that remains for obtaining $\langle 111\rangle$ textured material is to grow them with plane front solidification morphology.

Therefore, to explore the possibility of obtaining $\langle 111\rangle$ texture, we have studied in this article the planar growth of $(\mathrm{Tb}, \mathrm{Dy}) \mathrm{Fe}_{2}$ intermetallic in an alloy $\mathrm{Tb}_{0.3} \mathrm{Dy}_{0.7} \mathrm{Fe}_{1.95}$, by adopting the modified Bridgman technique. The orientation selection in samples grown in the plane front regime is studied in extensive detail to understand the mechanism that takes place at the solid-liquid interface. We also show the formation of complex microstructural patterns like peritectic coupled

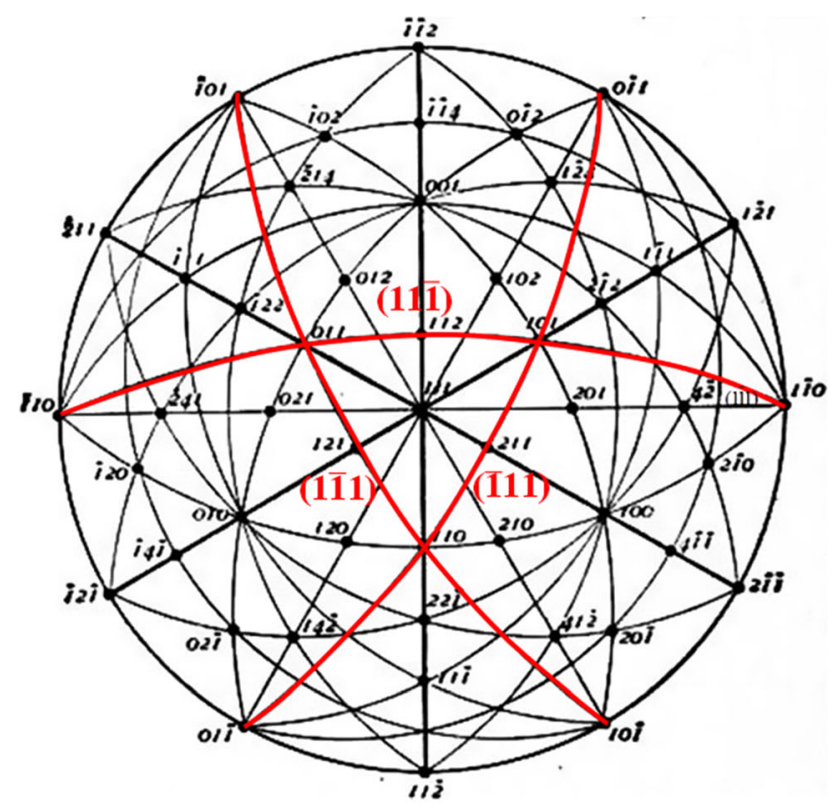

(a)

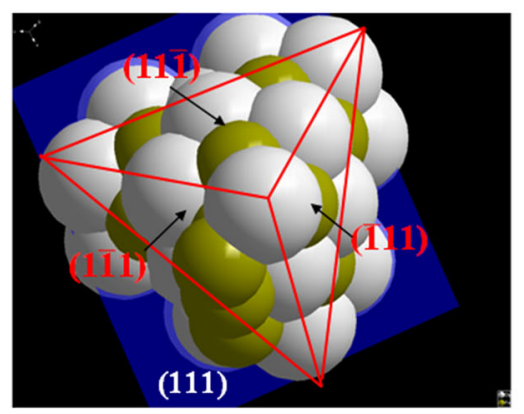

(b)

Fig. 1-Preferred growth configuration of $\langle 111\rangle$ in the cellular/dendritic regime: $(a)$ represented in a (111) stereogram and $(b)$ atomic configuration around growth direction. growth (PCG) and island banding, which are morphologically different from other peritectic alloys, ${ }^{[17-27]}$ and unveil the interplay among growth orientation, microstructure, and magnetostriction.

\section{EXPERIMENTAL SECTION}

$\mathrm{Tb}_{0.3} \mathrm{Dy}_{0.7} \mathrm{Fe}_{1.95}$ alloy was prepared by vacuum induction melting of the constituent elements (of purity $>99.5$ pct) in a recrystallized alumina crucible under a vacuum of $5 \times 10^{-5}$ mbar. The molten alloy was then subsequently cast into quartz tube molds in the form of 15-mm $\phi$ and 80-mm-long cylindrical rods. The rods were then directionally solidified by modified Bridgman technique using different growth rates varying from 5 to $100 \mathrm{~cm} / \mathrm{h}$. During directional solidification, the polycrystalline rods were placed inside quartz tube molds open at both ends and placed on a water-cooled $\mathrm{Cu}$ plate, keeping the bottom surface of the cast rod in contact. To maintain a high-temperature gradient throughout the process, auxiliary cooling arrangements by water-cooled $\mathrm{Cu}$ coil and forced Argon gas jet were used to extract heat from the already solidified rod. A schematic of the directional solidification setup used for the experiment is shown in Figure 2. The highest temperature gradient obtained during the process is $423 \mathrm{~K} / \mathrm{cm}\left(150^{\circ} \mathrm{C} / \mathrm{cm}\right)$. However, despite the presence of auxiliary cooling arrangements, a slight decrease of the temperature gradient up to $413 \mathrm{~K} / \mathrm{cm}\left(140{ }^{\circ} \mathrm{C} / \mathrm{cm}\right)$ was observed during the directional solidification process. No seed crystal was used to study the natural (unbiased) evolution of texture as a function of growth rate. In fact, the polycrystalline rod was placed on a water-cooled $\mathrm{Cu}$ plate to retain one thin unmelted polycrystalline layer at the bottom.

The microstructural features of the longitudinal sections of the directionally solidified samples were investigated by using a FEI Quanta 400 E-SEM scanning electron microscope (SEM). Detailed micro-chemical analysis was also carried out by using a WDS detector in an EPMA (M/s CAMECA make). Room-temperature static magnetostriction was measured under a dc magnetic field by using field-compensated resistance strain gauges. The evolution of texture during directional solidification at different rates was further characterized by using a texture goniometer. An Inel XRG 300 diffractometer coupled with a curved "position sensitive detector" was employed for this purpose. The pole figures were analyzed by using LABOTEX $^{\circledR}$ software for identification of various texture components. Since in a single pole figure all the components may not appear, a set of three pole figures viz. (220), (311), and (422) was generated for each sample.

\section{RESULTS AND DISCUSSION}

\section{A. Microstructural Features}

The BSE image of the longitudinal section of the sample directionally grown at $5 \mathrm{~cm} / \mathrm{h}$ is shown in 
Initial Position

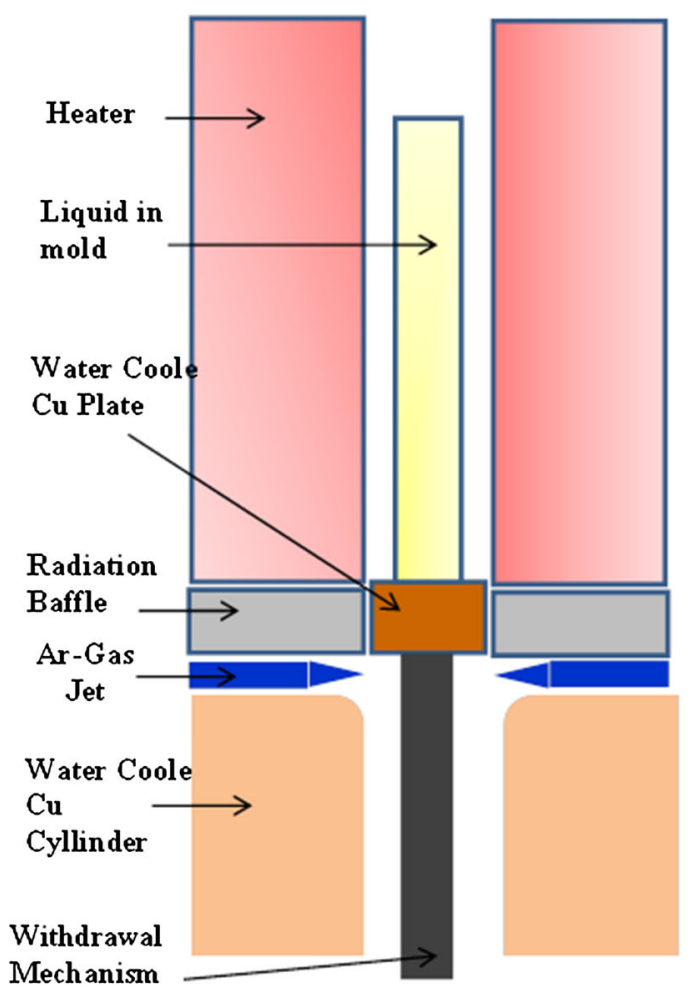

During Solidific ation

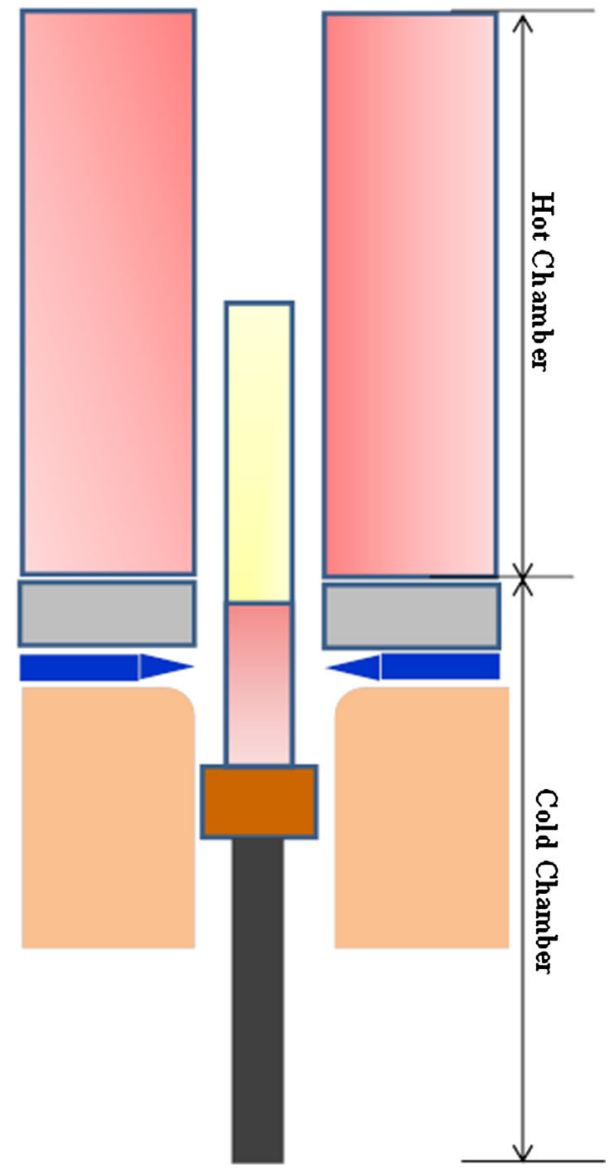

Fig. 2-Schematic of modified Bridgman setup used for the solidification experiments.

Figure 3. The micrograph depicts plane front solidification of the peritectic product phase $(\mathrm{Tb}, \mathrm{Dy}) \mathrm{Fe}_{2}$ and discrete appearance of the blocky pro-peritectic $(\mathrm{Tb}, \mathrm{Dy}) \mathrm{Fe}_{3}$ phase occasionally in some regions. When the growth rate is increased, the absence of the pro-peritectic phase is observed (Figure 4) near the bottom portion (closer to the chilled end). However, after a certain growth distance, the pro-peritectic phase starts appearing as islands oriented perpendicular to the growth direction (Figure 4). Further away from the chilled end, the pro-peritectic phase is found to be formed parallel to the growth direction (Figure 4), which is similar to the PCG morphology reported for $\mathrm{Fe}-\mathrm{Ni}$ alloys. ${ }^{[24,25]}$ The appearance of PCG becomes prominent with an increase in growth rate. However, the PCG observed in our alloy is irregular in nature compared with the regular alternate lamellae of peritectic and pro-peritectic phases reported for other peritectic alloy systems. ${ }^{[18,23-25]}$ The plane front growth is stable over the entire $80 \mathrm{~mm}$ length of the sample in the case of growth rates of 5 to $80 \mathrm{~cm} / \mathrm{h}$. However, for the $90 \mathrm{~cm} / \mathrm{h}$ sample, the growth is predominantly planar with occasional instability, which begins to be observed almost at the same location as the onset of PCG.

The plane front solidification morphology of $(\mathrm{Tb}, \mathrm{Dy}) \mathrm{Fe}_{2}$ changes to cellular when the growth rate is increased to $100 \mathrm{~cm} / \mathrm{h}$ (Figure 5(a)) with a marked absence of the pro-peritectic phase. The cellular instability is observed right from the chilled end of the directionally solidified sample. A solid solution of $\mathrm{Tb}$ and Dy is found to be distributed along the intercellular boundaries, which yield a bright contrast in the micrograph (Figure 5(a)). The solid solution is a product of a divorced eutectic reaction $[\mathrm{L} \rightarrow(\mathrm{Tb}$, Dy)-solid solution $\left.+(\mathrm{Tb}, \mathrm{Dy}) \mathrm{Fe}_{2}\right]$. The liquid that solidified last at the intercellular region undergoes this reaction. The micro-chemical analyses of the cell and intercellular boundary regions have been carried out by EPMA. The composition profile across a cell is shown in Figure 5(b). The line profiles indicate complete absence of $\mathrm{Fe}$ in the intercellular region. It is also evident from the line profiles that the interface between the cell and the cell boundary is sharp (Figure 5(b)).

The island-like features observed in the samples grown at $10-90 \mathrm{~cm} / \mathrm{h}$ and the blocky appearance of the pro-peritectic phase observed in the sample grown at $5 \mathrm{~cm} / \mathrm{h}$ resemble the morphology corresponding to island banding or discrete banding reported earlier for peritectic alloys. ${ }^{[23-25]}$ This morphology of banding emerges due to nucleation of one phase (peritectic product or pro-peritectic) ahead of the other phase. The condition of band formation persists until both phases 


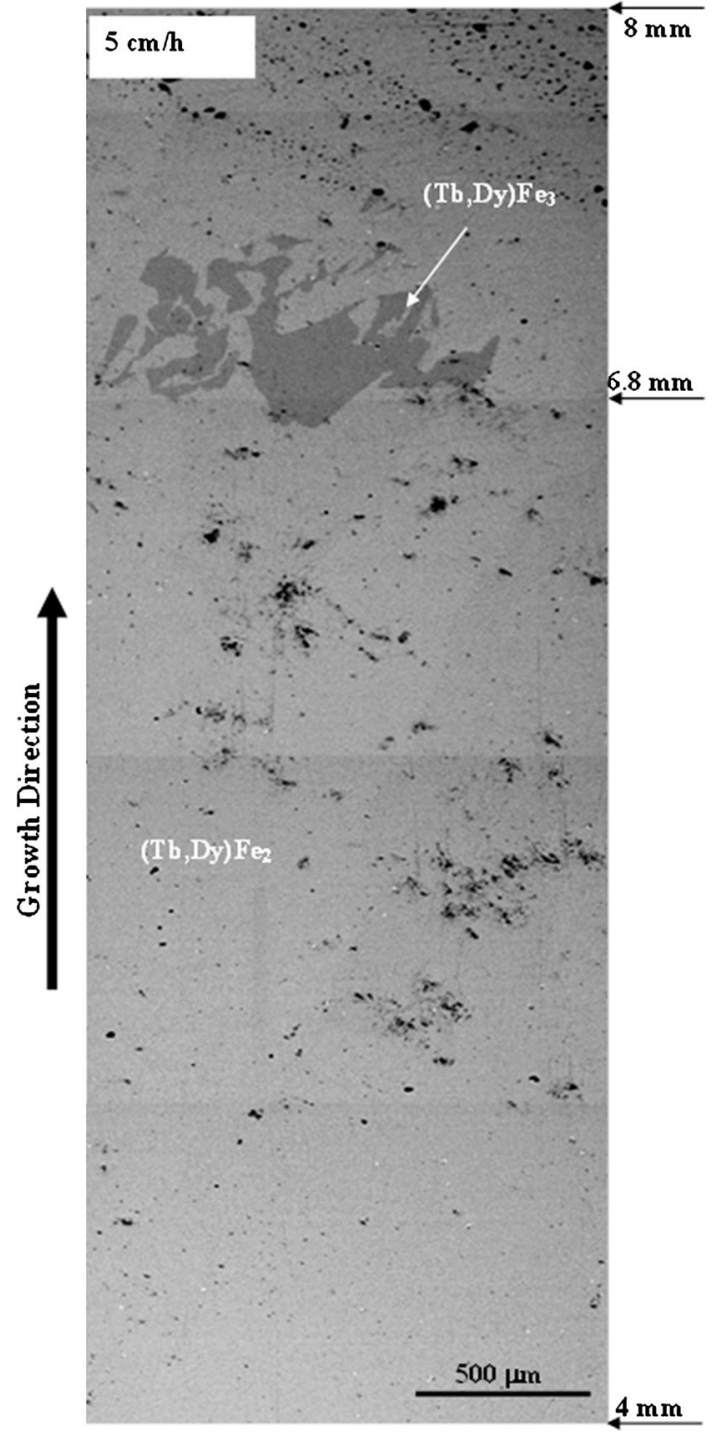

Fig. 3-The microstructure of the longitudinal section of the sample directionally grown at $5 \mathrm{~cm} / \mathrm{h}$ depicting the blocky appearance of the pro-peritectic (Tb,Dy)Fe3 phase. The distances indicated in the figure are measured from the chilled end.

are morphologically stable under the imposed value of $\mathrm{G} / \mathrm{v}$. We note that phase field simulations ${ }^{[25]}$ have predicted that the island banding can lead to PCG. In the present study, PCG is found to initiate from bands except for the sample grown at $5 \mathrm{~cm} / \mathrm{h}$. The same study $^{[25]}$ also indicates that the island/discrete banding leads to PCG after a fewer layers when the volume fraction of the pro-peritectic phase is low. In the case of the present study, the volume fraction of the pro-peritectic phase is much less, and accordingly, in most cases, the PCG is found to initiate only after one layer of discrete/island banding. The morphology of the PCG observed in this study is irregular and resembles the morphology observed during irregular eutectic growth in the directionally solidified $\mathrm{Al}-\mathrm{Si}$ and $\mathrm{Fe}-\mathrm{C}$ alloys. ${ }^{[28-30]}$ In the case of irregular eutectics, generally one of the growing phases is either an intermetallic compound or a covalently bonded phase (having high entropy of fusion), which exhibits strong anisotropy of growth along a particular direction. As a result, the regular lamellar eutectic growth is disrupted and irregular eutectic forms. Similarly, in the present study, both the pro-peritectic phase $\left[(\mathrm{Tb}, \mathrm{Dy}) \mathrm{Fe}_{3}\right]$ and the peritectic product phase $\left[(\mathrm{Tb}, \mathrm{Dy}) \mathrm{Fe}_{2}\right]$ are intermetallic phases. The $(\mathrm{Tb}, \mathrm{Dy}) \mathrm{Fe}_{2}$ is in cubic Laves phase (space group $F d \overline{3} m$ ), and the pro-peritectic (Tb,Dy)Fe $\mathrm{Fe}_{3}$ is in the rhombohedral Laves phase (space group $R \overline{3} m$ ). Thus, irregular coupled growth morphology is observed instead of regular peritectic coupled growth with alternate lamellae of phases.

The study of microstructure reveals that plane front solidification morphology of ( $\mathrm{Tb}, \mathrm{Dy}) \mathrm{Fe}_{2}$ is stable over a wide range of growth rates $(5-90 \mathrm{~cm} / \mathrm{h})$, and therefore, it is ideal for investigating the evolution of texture in the plane front growth regime.

\section{B. Texture Studies}

The X-ray pole figures obtained from the directionally solidified rods that correspond to different pulling rates are shown in Figure 6. The description of the texture components, as observed in (220), (422), and (311) pole figures, is presented briefly as a function of solidification rates.

\section{Samples grown at 5 to $30 \mathrm{~cm} / \mathrm{h}$}

The (311) pole figure (Figure 6) of the sample grown at $5 \mathrm{~cm} / \mathrm{h}$ exhibits a very strong intensity contour at the center $(\chi=0)$, indicating the presence of a strong $\langle 311\rangle$ orientation in this directionally solidified sample. This is in agreement with an earlier report on the texture evolution during directional solidification of Ho-Tb-Fe. ${ }^{[31]}$ The intensity of the $\langle 311\rangle$ texture component decreases as the growth rate is increased, but it remains one of the major texture components until the growth rate of $30 \mathrm{~cm} / \mathrm{h}$. As the growth rate increases, the major texture component $\langle 311\rangle$ is accompanied by minor components such as $\langle 110\rangle$ and $\langle 331\rangle$. Considering the fact that the texture may evolve within \pm 15 deg from the geometric axis of the directionally solidified samples, ${ }^{[32]}$ the texture component $\langle 331\rangle$ will be termed hereafter as "rotated $\langle 110\rangle$ " as it is only 13 deg away from $\langle 110\rangle$. The intensity of $\langle 110\rangle$ and "rotated $\langle 110\rangle$ " components increases with growth, and in the case of the sample grown at $30 \mathrm{~cm} / \mathrm{h}$, their intensities become comparable with that of $\langle 311\rangle$ (Figure 6). Additionally, a weak texture component $\langle 531\rangle$ emerges at a $30 \mathrm{~cm} / \mathrm{h}$ growth rate, which will be denoted hereafter as "rotated $\langle 112\rangle "$ as it is only 14 deg away from $\langle 112\rangle$.

\section{Samples grown at $40-70 \mathrm{~cm} / \mathrm{h}$}

The sample directionally solidified at $40 \mathrm{~cm} / \mathrm{h}$ exhibits the increase in intensity of $\langle 110\rangle$, "rotated $\langle 110\rangle$, ," and "rotated $\langle 112\rangle$ " components (Figure 6). The "rotated $\langle 112\rangle$ " texture component becomes dominant at a growth rate of $50 \mathrm{~cm} / \mathrm{h}$, and the intensity of the $\langle 110\rangle$ component becomes subdued. The presence of the major component "rotated $\langle 112\rangle$ " is evident from the presence of the high-intensity locations at $\chi=19.1$ and $77.2 \mathrm{deg}$ 


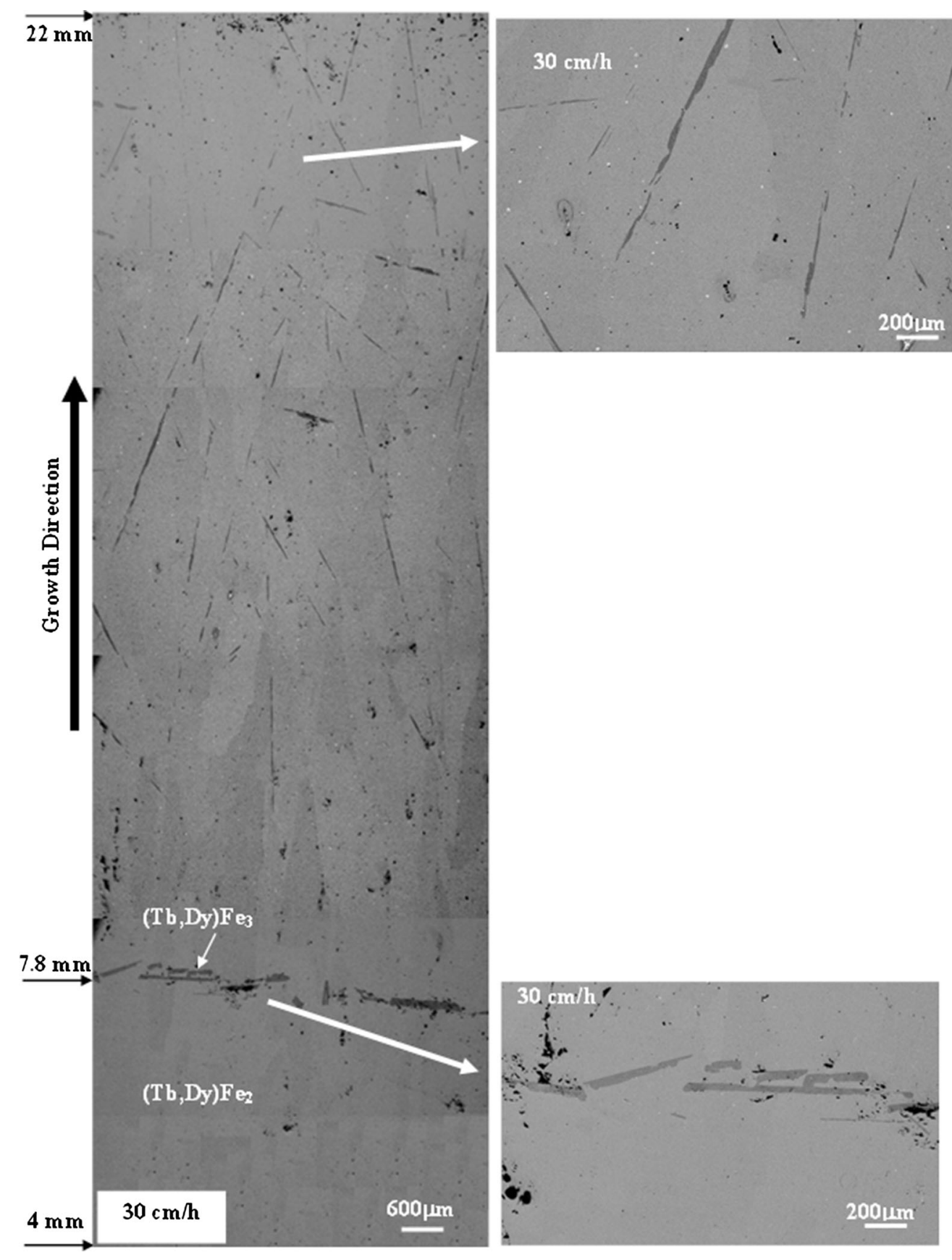

Fig. 4-The microstructure of the longitudinal section of the sample directionally grown at $30 \mathrm{~cm} / \mathrm{h}$ depicting PCG as dominant growth morphology. The distances indicated in the figure are measured from the chilled end.

in the (220) pole figure (Figure 6). The $\langle 110\rangle$ texture component becomes completely absent in the sample grown at $60 \mathrm{~cm} / \mathrm{h}$; instead, the $\langle 112\rangle$ texture component starts appearing in this growth rate. The intensity of $\langle 112\rangle$ and "rotated $\langle 112\rangle$ " texture components become more prominent when the growth rate is increased subduing the intensities of $\langle 110\rangle$ and "rotated $\langle 110\rangle$," which indicates a clear transition of preferred growth direction to $\langle 112\rangle$ with an increase in growth rate.

\section{Samples grown at $80-100 \mathrm{~cm} / \mathrm{h}$}

In this growth regime, $\langle 112\rangle$ emerges as a prominent texture component along with "rotated $\langle 112\rangle$ " (Figure 6). The $\langle 311\rangle$ component is completely absent in this growth regime, but the intensity of $\langle 112\rangle$ increases with the growth rate and it becomes very strong for the sample grown at $100 \mathrm{~cm} / \mathrm{h}$.

A summary of the texture components observed in different samples is presented in Table I. 


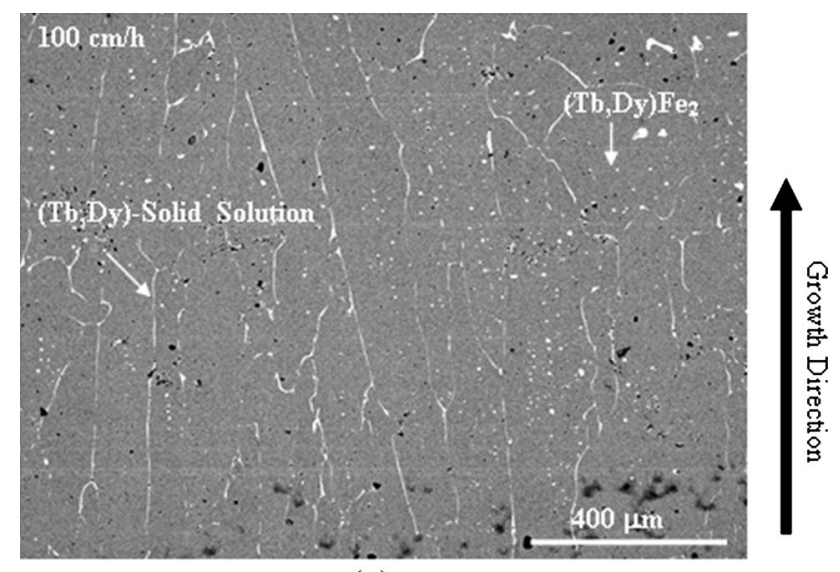

(a)

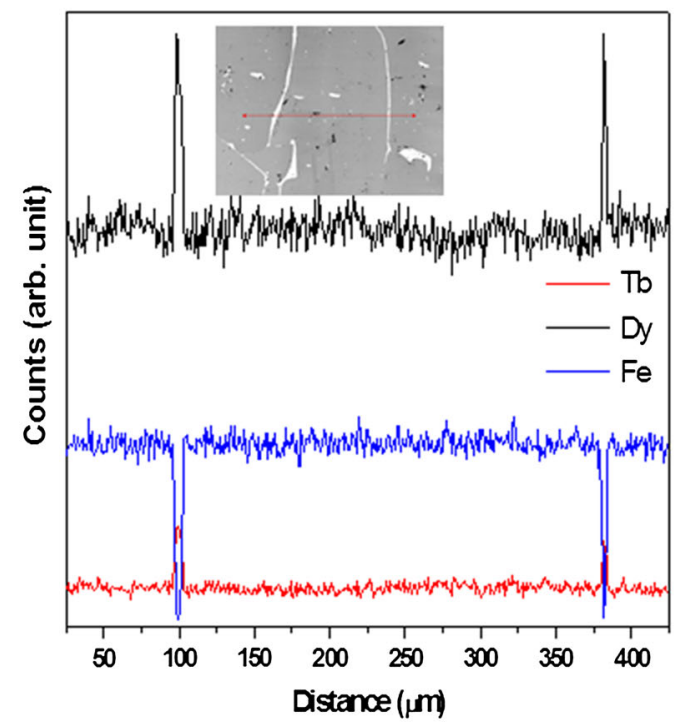

(b)

Fig. 5-The microstructure of the longitudinal section of the sample directionally grown at $100 \mathrm{~cm} / \mathrm{h}(a)$ indicating cellular solidification morphology of (Tb,Dy)Fe2 and (b) the plot of elemental composition (determined by EPMA analysis) across the cell and cell boundaries.

On the basis of the summary of texture presented in Table I, the growth process can be clearly divided into three texture regimes. At lower growth rates $(5-30 \mathrm{~cm} /$ h), $\langle 311\rangle$ components evolve as dominant texture components; in the intermediate growth rate regime $(40-70 \mathrm{~cm} / \mathrm{h})$, the $\langle 110\rangle$ and rotated $\langle 110\rangle$ components do; and at a higher growth regime $(80-100 \mathrm{~cm} / \mathrm{h}),\langle 112\rangle$ and rotated $\langle 112\rangle$ components evolve as dominant texture components.

\section{Orientation Selection with Growth Rate}

The present study indicates formation of $\langle 311\rangle$ as a prominent texture component at lower growth rates (5 and $10 \mathrm{~cm} / \mathrm{h}$ ). The analysis of the microstructure observed during the present study indicates plane front solidification of major phase (Tb, Dy)Fe $\mathrm{Fe}_{2}$ for a wide range of solidification rates. Since in the case of plane front growth the solid-liquid interface is formed by the plane normal to the growth direction, the orientation selection should occur based on the atomic packing density of the plane, normal to the growth direction. Therefore, to understand the orientation selection, it is important to understand the atomic packing density of the individual planes facing liquid at the planar interface.

The atomic packing density of the $\{311\}$ plane of (Tb,Dy)Fe $\mathrm{F}_{2}$ is 85 pct, which is higher than the atomic packing density of $\{110\}$ (81 pct) and $\{112\}$ (71 pct) planes, respectively (Table II). Therefore, there will be kinetic disadvantage in the growth of the $\{311\}$ plane through atomic attachment compared with the $\{110\}$ and $\{112\}$ planes as more mass transport is needed for the former plane to grow an equivalent amount. Thus, $\langle 311\rangle$ emerges as a favored texture component at a lower growth rate, which subsequently changes to $\langle 110\rangle$ with an increase in growth rate. With a further increase of growth rate, $\langle 112\rangle$ emerges as the dominant texture component.

Our results indicate that at a lower growth rate, more time is available for mass transport, and hence, a plane with a higher packing density that will have lower surface energy will be preferred. It can be seen from Table II that the $\{111\}$ planes have still a higher packing density (95 pct) compared with (311). Therefore, it is expected that $\langle 111\rangle$ should appear as the preferred growth direction as the growth rate decreases, which is different from the present observation. This is, however, consistent with the earlier result, ${ }^{[16]}$ which shows (Tb, Dy) $\mathrm{Fe}_{2}$ can be grown along the $\langle 111\rangle$ direction by using an extremely slow crystal pulling rate in the Czochralski method.

To understand the growth of $\langle 311\rangle$ in preference to $\langle 111\rangle$, in the present study, the stacking sequence of $\{311\}$ planes has been studied and compared with that of $\{111\}$ planes (Figure 7). It is observed that all the layers in the stacking sequence of $\{311\}$ planes are identical and have a population of both rare earth and iron atoms (Figure 7). However, one of the layers in the stacking sequence of $\{111\}$ planes consists of only $\mathrm{Fe}$ atoms (Figure 7). Therefore, atomic attachment to the $\{311\}$ interface is kinetically more favorable as compared with the $\{111\}$ interface. Furthermore, the (311) interface can be resolved into two $\{111\}$ type planes. Figure 8 shows a closer view of a typical (311) interface, which can be resolved into (111) and (111) planes. The (111) is of the type layer I (Figure 7) of $\{111\}$ planes, whereas (111) plane is of the type layer II (Figure 7) of $\{111\}$ planes. The (111) [type I] plane consists of $0.079 R$ $(R=\mathrm{Tb}$ and $\mathrm{Dy})$ atoms and $0.036 \mathrm{Fe}$ atoms per unit area, whereas the (111)[type II] plane consists of only $0.131 \mathrm{Fe}$ atoms per unit area. Therefore, considering (111) and (111) planes together, the total number $\mathrm{R}$ atoms per unit area is 0.079 and the total number $\mathrm{Fe}$ atoms per unit area is $0.167(=0.036+0.131)$. Therefore, in this configuration, the ratio of total $\mathrm{Fe} / \mathrm{R}$ atoms is approximately 2 , which is closer to the stoichiometric composition $\mathrm{RFe}_{2}$. Therefore, simultaneous atomic attachment to two different types of $\{111\}$ planes during growth can result in formation of the $\{311\}$ planar 


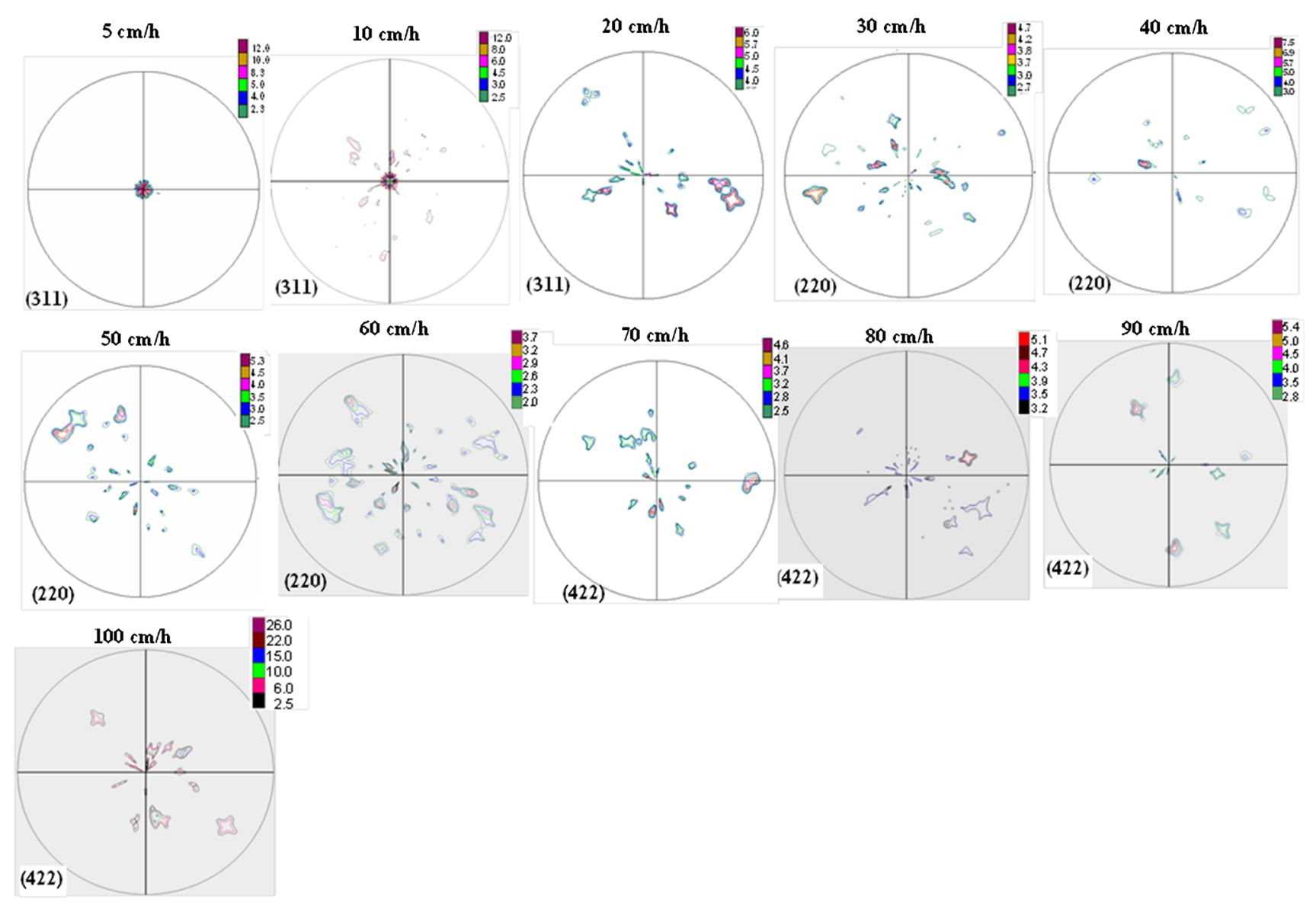

Fig. 6-Pole figures of samples directionally grown at $5-100 \mathrm{~cm} / \mathrm{h}$, indicating change in preferred growth direction with growth rate. The pole figures were obtained from the transverse section of the sample taken at $40 \mathrm{~mm}$ away from the chilled end.

Table I. Major Texture Components Observed in the Samples Directionally Grown at Different Rates

\begin{tabular}{lc}
\hline Growth Rate $(\mathrm{cm} / \mathrm{h})$ & Major Texture Components \\
\hline 5 & $\langle 311\rangle$ \\
10 & $\langle 311\rangle$ \\
20 & $\langle 311\rangle,\langle 110\rangle$, rotated $\langle 110\rangle$ \\
30 & $\langle 110\rangle$, rotated $\langle 110\rangle,\langle 311\rangle$ \\
40 & $\langle 110\rangle$, rotated $\langle 110\rangle$, \\
& rotated $\langle 112\rangle,\langle 311\rangle$ \\
50 & rotated $\langle 112\rangle,\langle 110\rangle$, \\
& rotated $\langle 110\rangle$ \\
60 & rotated $\langle 112\rangle,\langle 112\rangle,\langle 110\rangle$ \\
70 & rotated $\langle 112\rangle,\langle 112\rangle$ \\
80 & rotated $\langle 112\rangle,\langle 112\rangle$ \\
90 & $\langle 112\rangle$, rotated $\langle 112\rangle$ \\
100 & $\langle 112\rangle$, rotated $\langle 112\rangle$ \\
\hline
\end{tabular}

solid-liquid interface with no partition of the solutes in the melt along the growth direction. In the case of plane front growth of the $\{111\}$ plane, the kinetic of growth will require rearrangement of atoms to develop sequentially the layers of two different types: (1) mixed population of $\mathrm{R}$ and $\mathrm{Fe}$ and (2) only Fe atoms. This requirement of rearrangement will act as a barrier to growth that will restrict the plane front growth of the $\{111\}$ interface compared with the $\{311\}$ interface. Only
Table II. Planar Packing Density for Different Planes of C15 Laves Phase (Tb,Dy)Fe 2

\begin{tabular}{lc}
\hline Planes & Planar Packing Density (pct) \\
$\{111\}$ & 95 \\
$\{311\}$ & 89 \\
$\{110\}$ & 81 \\
$\{100\}$ & 78 \\
$\{112\}$ & 71 \\
\hline
\end{tabular}

at an extremely slow growth rate, it may be possible to obtain $\langle 111\rangle$ growth texture, as observed earlier ${ }^{[16]}$ by slow crystal pulling in the Czochralski technique. A schematic sketch depicting comparison of kinetics of atomic attachment at the solid-liquid interface of $\langle 111\rangle$ and $\langle 113\rangle$ growth is shown in Figure 9.

\section{Magnetostriction}

The magnetostriction of the DS samples was measured parallel to the growth direction at an applied field of $5 \mathrm{kOe}$ and is plotted as a function of the solidification rate in Figure 10(a). The direction of the applied magnetic field is also parallel to the growth direction. The figure indicates that the magnetostriction of most of the sample falls in the range of 1250-1300 microstrains. 
(311) Planes

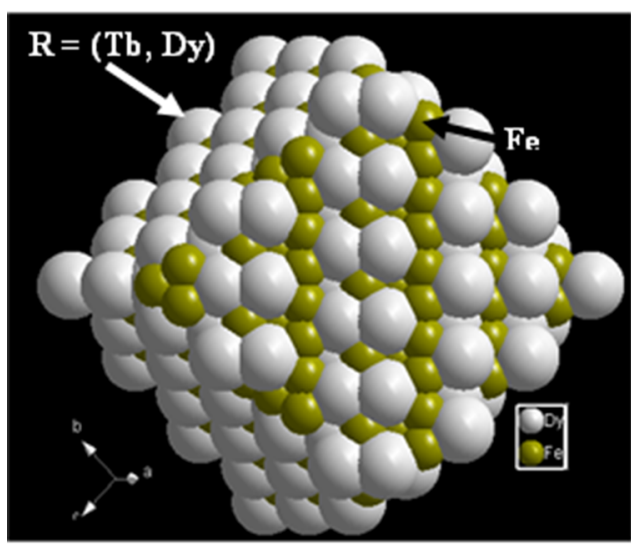

(111) Planes
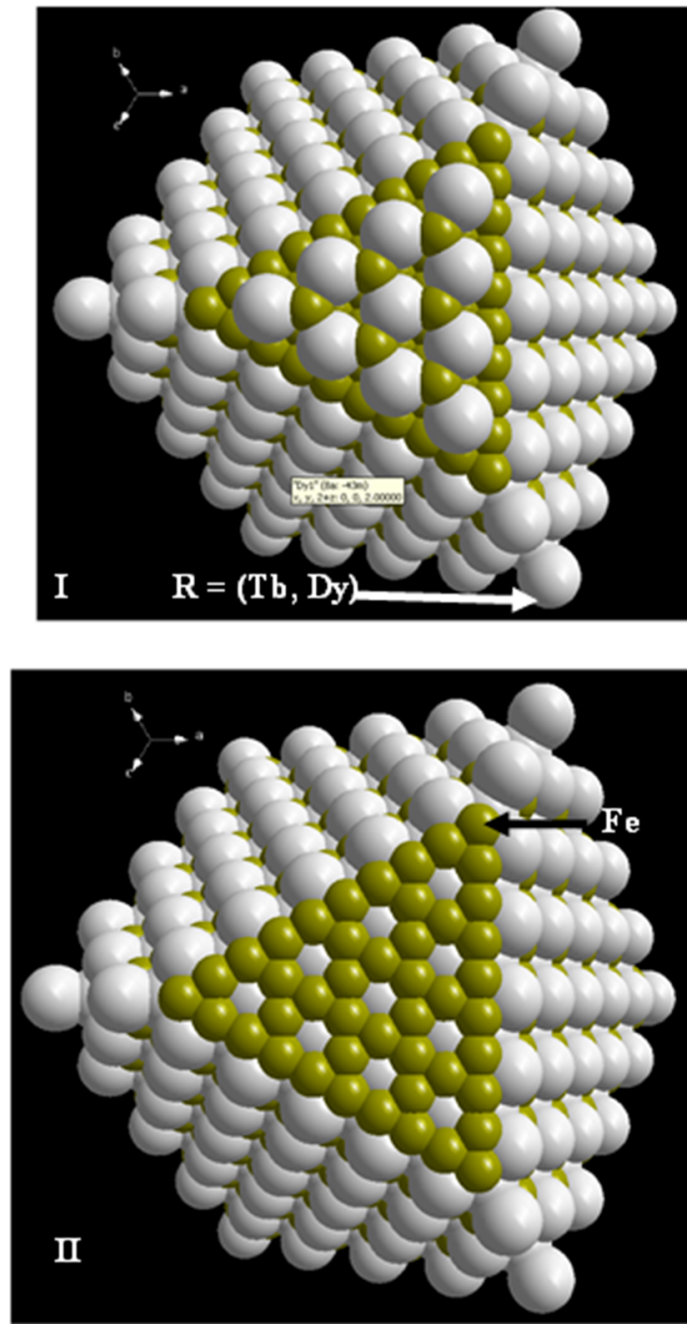

Fig. 7-Atomic population in individual stacks of (311) and (111) planes generated using Diamond 3.2 software.

The sample grown at $100 \mathrm{~cm} / \mathrm{h}$, however, exhibits a large improvement in magnetostriction (1400 microstrains) owing to the absence of the pro-peritectic $(\mathrm{Tb}, \mathrm{Dy}) \mathrm{Fe}_{3}$ phase. The values of the initial slopes of the magnetostriction curve $(\mathrm{d} \lambda / \mathrm{dH})$, known as the static strain coefficient, are plotted in Figure 10(b) as a function of the solidification rate. The static strain coefficient is generally governed by three factors: (1) presence/absence of (Tb,Dy) $\mathrm{Fe}_{3}$, (2) texture, and (3) magneto-crystalline anisotropy. Since all the solidification experiments were carried out with alloy of the same composition, the effect of magneto-crystalline anisotropy can be neglected. The sample grown at $100 \mathrm{~cm} / \mathrm{h}$ only exhibits complete absence of the pro-peritectic (Tb,Dy) $\mathrm{Fe}_{3}$ phase. Accordingly, this sample exhibits the highest slope. However, considerable variations in the value of the static strain coefficient could be observed for the samples grown at other solidification rates. Since all those samples exhibit the presence of a nearly similar amount of the $(\mathrm{Tb}, \mathrm{Dy}) \mathrm{Fe}_{3}$ phase, the variation in slope is attributed to the presence of different texture components in different samples.
To understand the variation in the static strain coefficient, the texture components observed in different samples have been plotted on a quadrant of the (111) stereogram (Figure 11). Since $\langle 111\rangle$ is the EMD of $(\mathrm{Tb}, \mathrm{Dy}) \mathrm{Fe}_{2}$, the plot on the (111) stereogram (Figure 11) clearly depicts the deviation of different texture components from EMD. The minimum angles between EMD and different texture components are also presented in the same figure. The slope is found to be more for the samples having a texture component closer to EMD. Therefore, the slope is highest for the sample solidified at $100 \mathrm{~cm} / \mathrm{h}$, owing to the presence of strong $\langle 112\rangle$ texture components, which is only 19 deg away from EMD. The slope decreases due to the presence of $\langle 331\rangle,\langle 531\rangle,\langle 311\rangle$, and $\langle 110\rangle$ components, which are more deviated from EMD than $\langle 112\rangle$. Accordingly, the static strain coefficient values of the sample grown at 5 and $10 \mathrm{~cm} / \mathrm{h}$ are more compared with those grown at a growth rate of 20 and $30 \mathrm{~cm} / \mathrm{h}$ owing to the presence of $\langle 311\rangle$ (30 deg away from EMD) as a major texture component in first two samples, while the $\langle 110\rangle$ texture component (35 deg away from EMD) is present in later 

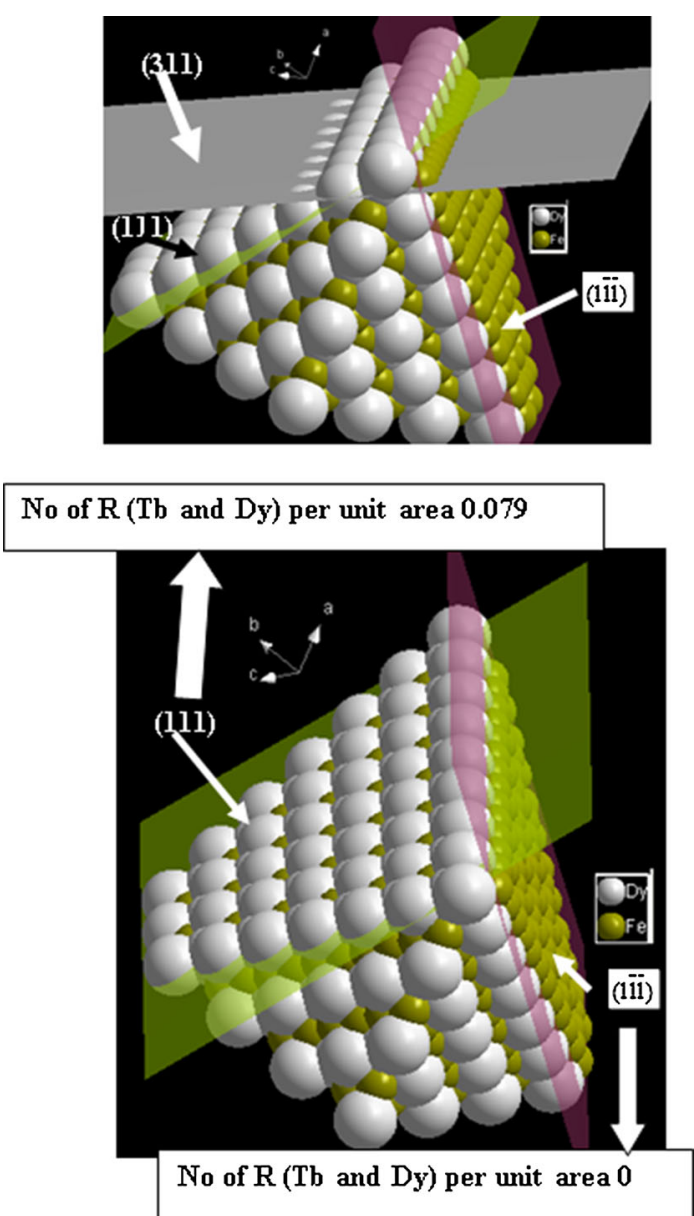

Fig. 8-Configuration of (311) interface: resolved into two $\{111\}$ type planes.

cases (Figure 11). With further increases in the pulling rate during Bridgeman growth, the $\langle 110\rangle$ component gets subdued and "rotated $\langle 112\rangle$ " and $\langle 112\rangle$ components become dominant. This results in the increase in the static strain coefficient.

\section{SUMMARY AND CONCLUSIONS}

The $\mathrm{Tb}_{0.3} \mathrm{Dy}_{0.7} \mathrm{Fe}_{1.95}$ alloy was directionally solidified by a modified Bridgman technique at different pulling rates ranging from 5 to $100 \mathrm{~cm} / \mathrm{h}$. The evolution of microstructure and texture with an increase in growth rate has been studied and correlated with magnetostriction.

1. The microstructure of the directionally grown sample exhibits planar solidification morphology of the $(\mathrm{Tb}, \mathrm{Dy}) \mathrm{Fe}_{2}$ phase for a wide range of solidification rates $(5-80 \mathrm{~cm} / \mathrm{h})$. Samples grown with plane front morphology exhibit the presence of islands/discrete bands of the pro-peritectic $(\mathrm{Tb}, \mathrm{Dy}) \mathrm{Fe}_{3}$ phase, toward the chilled end of the sample, which change into irregular coupled growth of (Tb,Dy) $\mathrm{Fe}_{3}$ and $(\mathrm{Tb}, \mathrm{Dy}) \mathrm{Fe}_{2}$ as the distance from the chilled end increases.
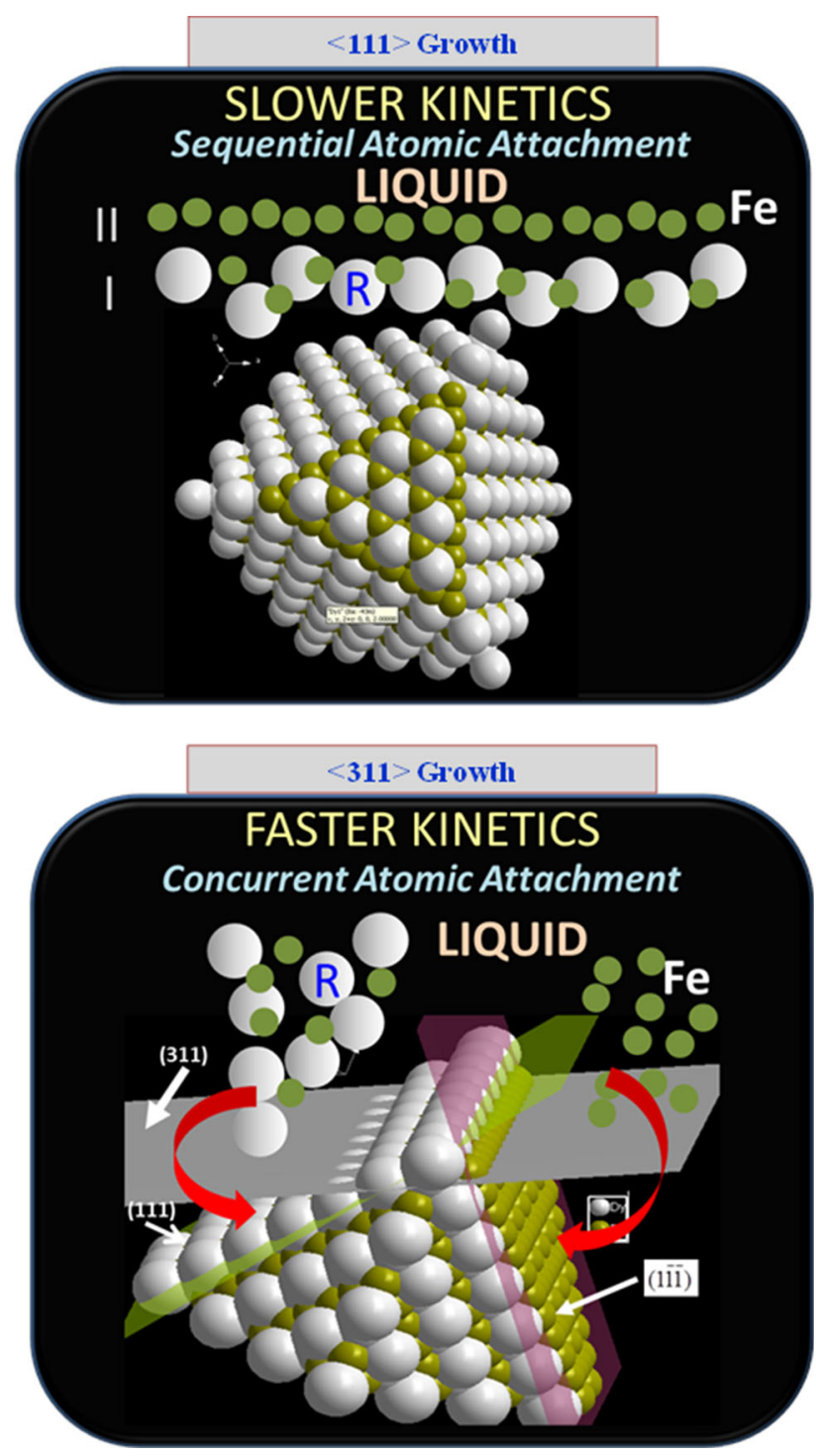

Fig. 9-Comparison of atomic attachment kinetics at (111) and (311) interfaces.

2. The texture study reveals that at lower growth rates $(5-30 \mathrm{~cm} / \mathrm{h}),\langle 311\rangle$ is the dominant texture component, which changes into $\langle 110\rangle$ in the intermediate growth regime $(40-70 \mathrm{~cm} / \mathrm{h})$ and finally $\langle 112\rangle$ becomes the strong component at a higher growth regime $(80-100 \mathrm{~cm} / \mathrm{h})$.

3. The orientation selection with growth rate has been analyzed in light of atomic attachment kinetics to the solid-liquid interface. With the $\{311\}$ type planes being more close packed compared with the $\{110\}$ and $\{112\}$ planes, the atomic attachment to the $\{311\}$ planes is expected to be sluggish. As a result, $\langle 311\rangle$ evolves as a dominant texture component at lower growth rates, which subsequently changes to $\langle 110\rangle$ at the intermediate growth rate regime and to $\langle 112\rangle$ at the higher growth rate regime.

4. Although the $\{311\}$ planes are less close packed than the $\{111\}$ ones, $\langle 311\rangle$ grows in preference to 


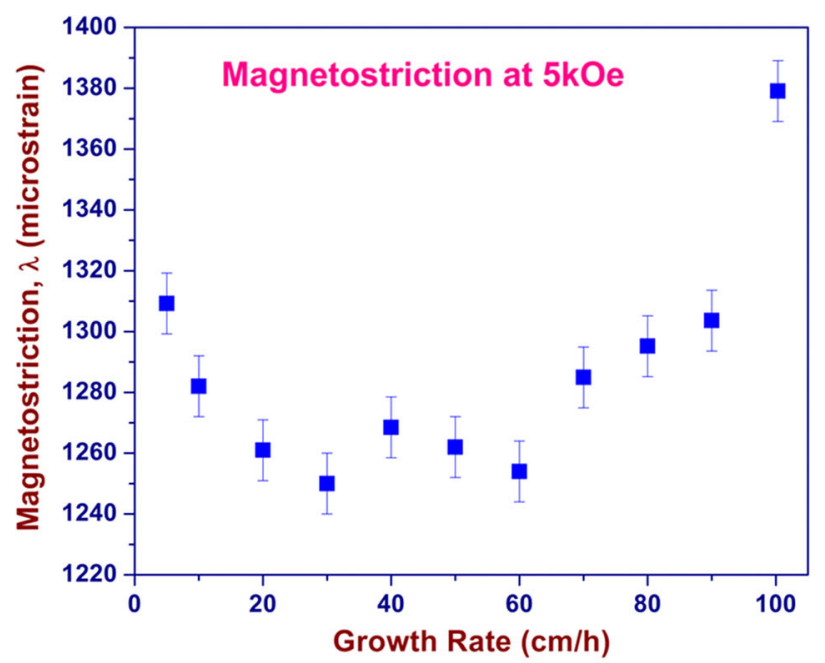

(a)

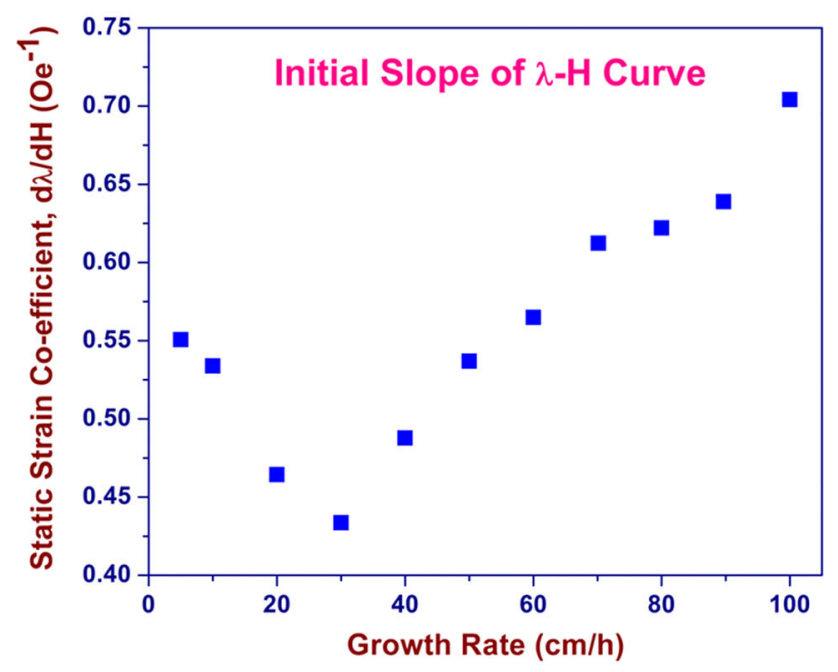

(b)

Fig. 10-(a) Magnetostriction ( $\lambda$ ) of directionally solidified samples measured at an applied field of $5 \mathrm{kOe}$ and $(b)$ the plot of slope $(\mathrm{d} \lambda /$ $\mathrm{d} H$ ) of the initial $\lambda-\mathrm{H}$ plot, plotted as a function of growth rate.

$\langle 111\rangle$ at a lower growth rate. The kinetics of atomic attachment to the $\{111\}$ plane is sluggish as the layers of two different types of stacks have to be grown in sequence, whereas the $\{311\}$ planes can be built by atomic attachment to two stacked $\{111\}$ planes in parallel, aiding a faster kinetics.

5. The sample solidified at $100 \mathrm{~cm} / \mathrm{h}$ exhibits the highest magnetostriction (1400 microstrains at 5 $\mathrm{kOe}$ ), which is attributed to a microstructure devoid of detrimental ( $\mathrm{Tb}, \mathrm{Dy}) \mathrm{Fe}_{3}$. The static strain coefficient values of the sample are found to be dependent on angular deviation of the major texture component from EMD. As a result, samples with $\langle 110\rangle(30$ deg away from EMD) as a major texture component exhibit a lower, and those with $\langle 112\rangle$ (19 deg away from EMD) as a major texture component display a higher, strain coefficient value.

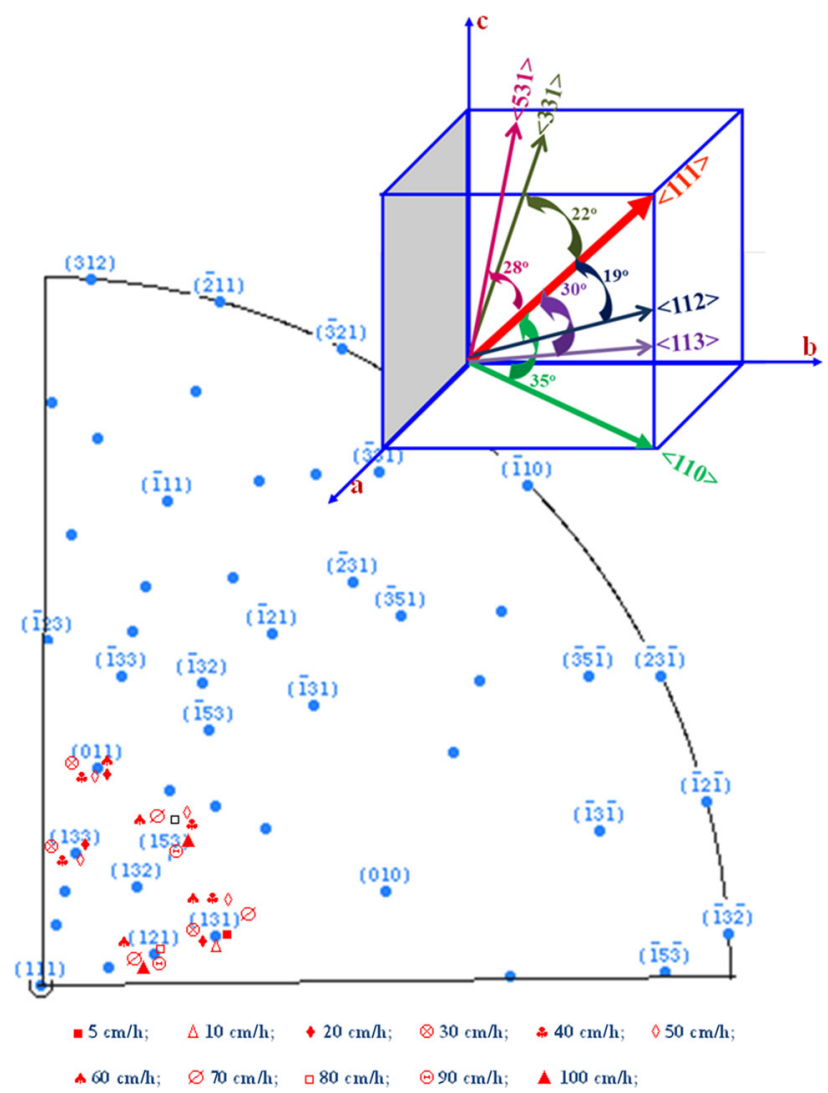

Fig. 11-Observed texture components of different samples plotted in a quadrant (111) stereogram and the deviation of different texture components from EMD.

\section{ACKNOWLEDGMENTS}

Financial support rendered by DRDO and the constant encouragement given by the Director at DMRL are greatly acknowledged. The technical support extended by Dr S.V. Kamat, Head of Functional Material Division of DMRL, is also gratefully acknowledged.

\section{REFERENCES}

1. A.E. Clark, H.S. Belson, and N. Tamagawa: AIP Conf. Proc., 1973, vol. 10, pp. 749-53.

2. K.H.J. Buschow: Rep. Prog. Phys., 1977, vol. 40, pp. 1179-1256.

3. N.C. Koon, C.M. Williams, and B.N. Das: J. Magn. Magn. Mater., 1991, vol. 100, pp. 173-85.

4. J.D. Verhoeven, E.D. Gibson, O.D. McMasters, and H.H. Baker: Metall. Trans. A, 1987, vol. 18, pp. 223-31.

5. J.D. Snodgrass and O.D. McMaster: J. Alloys Compd., 1997, vol. 258, pp. 24-29.

6. M. Palit, S. Pandian, R. Balamuralikrishnan, A.K. Singh, N. Das, V. Chandrasekharan, and G. Markandeyulu: J. Appl. Phys., 2006, vol. 100, pp. 074913-1-5.

7. J. Chengchang, L. Jianguo, M. Weizeng, and Z. Yaohe: J. Alloys Compd., 2002, vol. 333, pp. 291-95.

8. Y. Zhao, C. Jiang, H. Zhang, and H. Xu: J. Alloys Compd., 2003, vol. 354 , pp. 263-68. 
9. M. Palit, J.A. Chelvane, S. Pandian, N. Das, and V. Chandrasekaran: Scripta Mater., 2008, vol. 58, pp. 819-21.

10. M. Palit, J.A. Chelvane, H. Basumatary, S. Banumathy, A.K. Singh, S. Pandian, and V. Chandrasekaran: Intermetallics, 2010 , vol. 18, pp. 1027-32.

11. W. Mei, T. Okane, T. Umeda, and S. Zhou: J. Alloys Compd., 1997, vol. 248, pp. 151-58.

12. J.D. Verhoeven, E.D. Gibson, O.D. McMasters, and J.E. Ostenson: Metall. Trans. A, 1990, vol. 21, pp. 2249-55.

13. M. Palit, S. Banumathy, A.K. Singh, S. Pandian, and K. Chattopadhyay: Intermetallics, 2011, vol. 19, pp. 357-68.

14. W.J. Park, J.C. Kim, B.J. Ye, and Z.H. Lee: J. Cryst. Growth, 2000, vol. 212, pp. 283-90.

15. D. Kang, J. Liu, C. Jiang, and H. Xu: Cryst. Growth Des., 2016. DOI:10.1021/acs.cgd.5b00096.

16. G.-H. Wu, X.-G. Zhao, J.-H. Wang, J.-Y. Li, K.-C. Jia, and W.-S. Zhan: Appl. Phys. Lett., 1995, vol. 67, pp. 2005-07.

17. W. Löser, M. Leonhardt, H.G. Lindenkreuz, and B. Arnold: Mater. Sci. Eng. A, 2004, vol. 375, pp. 534-39.

18. M. Takeyama, Y. Yamamoto, H. Morishima, K. Koike, S.Y. Chang, and T. Matsuo: Mater. Sci. Eng. A, 2002, vol. 329, pp. 7-12.

19. M. Leonhardt, W. Löser, and H.G. Lindenkreuz: Acta Mater., 2002, vol. 50, pp. 725-34.

20. J. Strohmenger, T. Volkmann, J. Gao, and D.M. Herlach: Mater. Sci. Eng. A, 2004, vol. 375, pp. 561-64.
21. G. Phanikumar, K. Biswas, O. Funke, D. Holland-Moritz, D.M. Herlach, and K. Chattopadhyay: Acta Mater., 2005, vol. 53, pp. 3591-3600.

22. R. Trivedi: Scripta Mater., 2005, vol. 53, pp. 47-52.

23. O. Hunziker, M. Vandyoussefi, and W. Kurz: Acta Mater., 1998, vol. 46, pp. 6325-36.

24. S. Dobler, T.S. Lo, M. Plapp, A. Karma, and W. Kurz: Acta Mater., 2004, vol. 52, pp. 2795-2808.

25. T.S. Lo, S. Dobler, M. Plapp, A. Karma, and W. Kurz: Acta Mater., 2003, vol. 51, pp. 599-611.

26. R. Trivedi and J.H. Shin: Mater. Sci. Eng. A, 2005, vol. 413, pp. 288-95.

27. J.S. Park and R. Trivedi: J. Cryst. Growth, 1998, vol. 187, pp. $511-15$.

28. P. Magnin and W. Kurz: Acta Metall., 1987, vol. 35, pp. 111-28.

29. M. Gündüz, H. Kaya, E. Çadırlı, and A. Özmen: Mater. Sci. Eng. $A, 2004$, vol. 369, pp. 215-29.

30. H. Kaya, E. Çadırlı, M. Gündüz, and A. Ülgen: J. Mater. Eng. Perform., 2003, vol. 12, pp. 544-51.

31. J.A. Chelvane, S. Banumathy, M. Palit, H. Basumatary, A.K. Singh, and S. Pandian: J. Alloys Compd., 2010, vol. 507, pp. $162-66$.

32. M.G. Ardakani, N. D'Souza, A. Wagner, B.A. Shollock, and M. McLean: in Superalloys 2000, R.D. Kissinger, R.R. Bowman, K.A. Green, M. McLean, S. Olson, J.J. Schirra, and T.M. Pollock, eds., TMS, Warrendale, PA, 2000, pp. 219-28. 